\title{
Synthesis, Fluorescence and NMR Spectroscopic Studies of a Novel Phosphinoxido-18-crown-6 Ether Containing an Anthracene Fluorophore Unit
}

\author{
Hajnalka Szabó-Szentjóbi', Anna Márton¹, Dávid Pál', Gergő Dargó1,2, Áron Szigetvári, \\ Csaba Szántay³ , György Tibor Balogh², Tünde Tóth ${ }^{1,4}$, Péter Huszthy ${ }^{1 *}$ \\ 1 Department of Organic Chemistry and Technology, Faculty of Chemical Technology and Biotechnology, \\ Budapest University of Technology and Economics, H-1521 Budapest, P.O.B. 91, Hungary \\ ${ }^{2}$ Chemistry Department, Gedeon Richter Plc., H-1103 Budapest, Gyömrői út 19-21, Hungary \\ ${ }^{3}$ Spectroscopic Research Department, Gedeon Richter Plc., H-1475 Budapest, P.O.B. 27, Hungary \\ ${ }^{4}$ Institute for Energy Security and Environmental Safety, Centre for Energy Research, Hungarian Academy of Sciences, \\ H-1525 Budapest, P.O.B. 49, Hungary \\ *Corresponding author, e-mail: huszthy@mail.bme.hu
}

Received: 15 July 2019, Accepted: 04 September 2019, Published online: 17 October 2019

\begin{abstract}
The synthesis of the $(R, R)$ and $(S, S)$ enantiomers of a new enantiopure monophospha-18-crown-6 ether (1), which contains an anthracene fluorophore unit and methyl groups at its stereogenic centers, was accomplished. The structure of one enantiomer $\left((S, S)\right.$-1) was studied using one-dimensional $\left({ }^{1} \mathrm{H},{ }^{13} \mathrm{C}\left\{{ }^{1} \mathrm{H}\right\}\right.$, and $\left.{ }^{31} \mathrm{P}\left\{{ }^{1} \mathrm{H}\right\}\right)$ and two-dimensional NMR spectra. Because $(R, R)-\mathbf{1}$ and $(S, S)-\mathbf{1}$ can act as new fluorescent chemosensors, we examined their enantiomeric differentiation abilities toward the enantiomers of protonated chiral primary amines and amino acid esters (PEA, 1-NEA, PGME, PAME) using UV-Vis and fluorescence spectroscopies. These monophospha-crown ethers showed moderate enantiomeric discrimination abilities.
\end{abstract}

\section{Keywords}

crown ethers, fluorescence spectroscopy, sensor molecules, enantiomeric recognition

\section{Introduction}

Molecular recognition is a general phenomenon in Nature. There are many examples of its action, such as the enzyme-substrate interaction or the immunological response. These interactions are governed by non-covalent intermolecular forces between the host and the guest molecules [1-4]. Enantiomeric recognition is a special case of molecular recognition. Examples of its action include the metabolism of amino acids and sugars in biosynthetic pathways. The determination of enantiomeric compositions of biologically active chiral compounds has great importance, because the enantiomers may have very different physiological properties. Thus, chiral 'hosts' that can differentiate between enantiomeric guest molecules via some form of molecular recognition are always sought for, since they play an essential role in the analytical methods developed for the identification of enantiomers and the determination of enantiomeric ratios in non-racemic compositions. In particular, fluorescent chemosensors that contain a chiral unit and can selectively recognize enantiomers are highly useful in that regard, because they allow for the application of fluorescence spectroscopy, which is an excellent tool owing to its sensitivity, selectivity, versatility and relatively simple handing [5]. Because of this, the development of chiral fluorescent sensor molecules has gained much research interest. Among others, optically active crown ethers containing various fluorophore units were synthesized and their enantiomeric recognition abilities toward different chiral organic ammonium salts were examined [6]. Earlier we reported the preparation and evaluation of enantiopure crown ethers containing a pyridine or an acridine moiety or BODIPY linked azacrown ethers [7-12].

We and also other research groups prepared enantiopure crown ethers containing a $\mathrm{P}$ atom, but, to our best knowledge, there is none reported in which a fluorescent unit is attached directly to the phosphorus [13]. We wanted to observe how the phosphorus atom influence the 
photophysical properties and the enantiomeric recognition of this kind of sensor molecule.

In this paper we report the preparation of the $(R, R)$ and $(S, S)$ enantiomers of a new monophospha-18-crown-6 ether (1) containing an anthracene fluorophore unit, and having methyl groups at its stereogenic centers. [Note that the $(R, S)$ and $(S, R)$ forms involve diastereomeric as well as homomeric relationships if one considers the configuration of the $\mathrm{P}$ atom]. Also, we discuss our study into the complexation ability of $(R, R)-\mathbf{1}$ and $(S, S)-\mathbf{1}$ toward the hydrogen perchlorate salts of the enantiomers of 1-phenylethylamine (PEA), 1-(1-naphthyl)-ethylamine (1-NEA), phenylglycine methyl ester (PGME) and phenylalanine methyl ester (PAME) (Fig. 1) by UV/Vis and fluorescence spectroscopies. Our aim was to observe how this new structure of these host molecules influences the enantiomeric recognition toward the selected guest molecules.

\section{Results and discussion}

\subsection{Synthesis}

In order to obtain the $(R, R)$ and $(S, S)$ enantiomers of the new monophospha-18-crown-6 ether 1 , first the key intermediate ditosylates $(R, R)-\mathbf{2}$ and $(S, S)$-2 (Scheme 1) were synthesized. The reported ditosylate $(S, S)-\mathbf{2}[14]$ was prepared from ethyl $(S)$-lactate in a five-step synthesis $[15,16]$. Its unreported enantiomer $(R, R)-\mathbf{2}$ was synthesized from racemic propylene oxide, which was first hydrolyzed enantioselectively by Jacobsen's hydrolytic kinetic resolution procedure $[17,18]$ to give, besides the appropriate glycol, enantiopure $(R)$-propylene-oxide $(R)-3$. Epoxide $(R)-3$ was then allowed to react with the sodium salt of diethylene glycol to produce the corresponding tetraethylene glycol derivative $(R, R)-\mathbf{4}$ [15], which was tosylated to obtain $(R, R)-2$ [16]. Using pyridine as a base and solvent in the tosylation reaction, a higher yield was achieved than that reported for its enantiomer earlier applying $\mathrm{KOH}$ as a base [14] (Scheme 1).

Macrocyclization was carried out as described in the literature for similar compounds [16] by the reaction of the reported ethyl phosphinate 5 [19] and the ditosylates $(R, R)-2$ and $(S, S)-2$ at $50{ }^{\circ} \mathrm{C}$ in DMF using $\mathrm{K}_{2} \mathrm{CO}_{3}$ as a base to obtain $(S, S)-6$ and $(R, R)-6$ (Scheme 2). By applying these conditions the Williamson type ether formation takes place with total inversion of configuration.

Several procedures were tested in order to obtain the macrocycles containing an anthracene fluorophore unit $((R, R)-\mathbf{1}$ and $(S, S)-\mathbf{1})$. Using phosphinic acid chloride $(S, S)-7$, the coupling was unsuccessful with Grignard
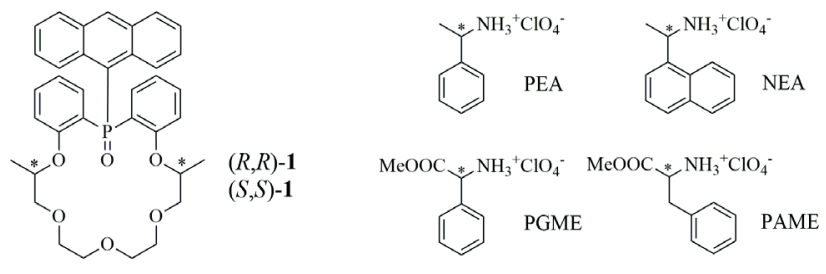

Fig. 1 Schematics of the enantiomers of monophospha-18-crown-6 ethers host molecules and the enantiomers of the chiral ammonium salt guests
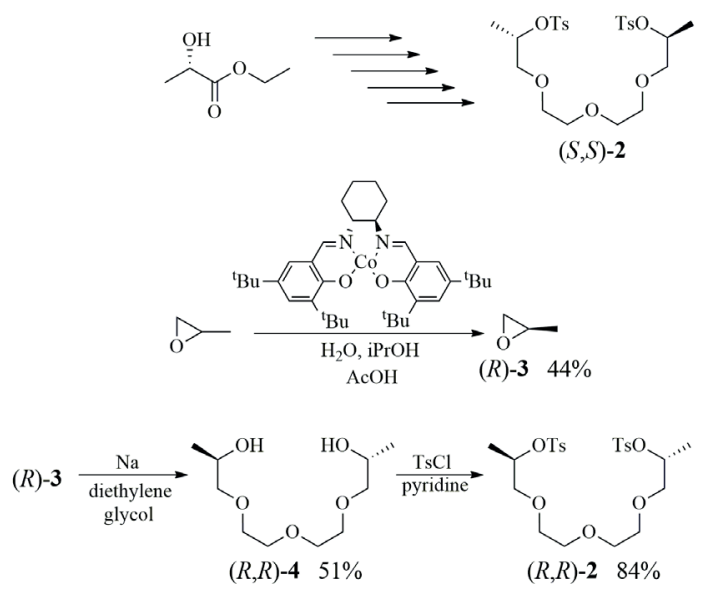

Scheme 1 Preparation of enantiopure key intermediates

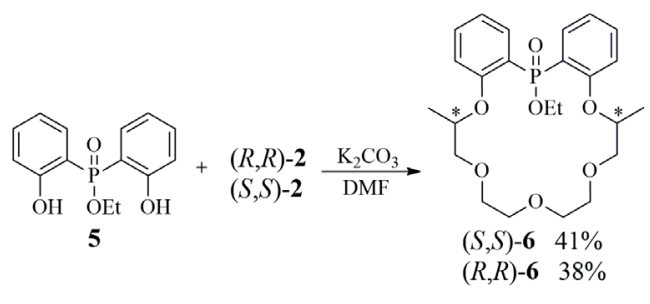

Scheme 2 Macrocyclization reaction

reaction (A) (Scheme 3). The desired product did not form although phenylmagnesium bromide was successfully coupled with acid chloride $(R, R)-7$ by this method [20]. Neither was the expected product obtained by the reaction with the lithium derivative of anthracene (B).

The preparation of the sensor molecules $(R, R)-\mathbf{1}$ and $(S, S)$-1 was successful from phosphine oxides $(R, R)-\mathbf{8}$ and $(S, S)-\mathbf{8}$ (Scheme 4). First, ethyl phosphinate $(S, S)-\mathbf{6}$ was reduced to phosphine oxide $(S, S)$-8 using sodium bis(2-methoxyethoxy)aluminum hydride $\left(\right.$ Red-Al $\left.{ }^{\circledR}\right)$ in toluene (C) (Scheme 4) [21-23]. A higher yield was achieved for this transformation by using lithium aluminum hydride in diethyl ether (D) [24], and because of this the reduction was also carried out by starting from $(R, R)-6$ (Scheme 4$)$. Using lithium aluminum hydride as a reducing agent the appropriate phosphine derivatives were obtained in the reactions directly ( ${ }^{31} \mathrm{P}-\mathrm{NMR}$ : $-73.97 \mathrm{ppm}$ ), which were oxidized by the air quantitatively to the phosphine oxides 


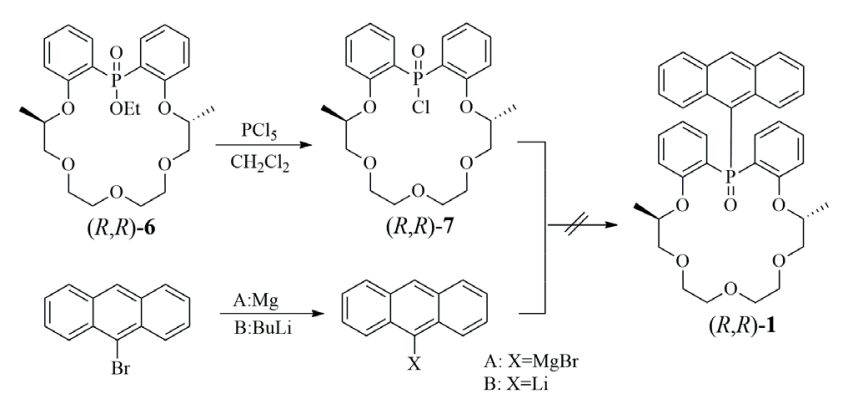

Scheme 3 Experiments on phosphorus-carbon coupling with organometallic reactions

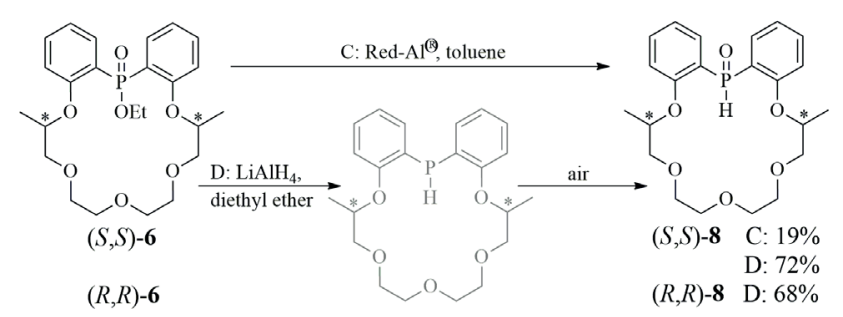

Scheme 4 Reduction of macrocycles containing an ethyl phosphinate unit

$(R, R)-8$ or $(S, S)-8\left({ }^{31} \mathrm{P}-\mathrm{NMR}: 9.12 \mathrm{ppm}\right)$ during the work up and purification.

Phosphine oxide derivatives $(R, R)-\mathbf{8}$ and $(S, S)-\mathbf{8}$ were converted to macrocycles $(R, R)-\mathbf{1}$ and $(S, S)$-1 containing an anthracene fluorophore unit using anthracene boronic acid (E) or by the Hirao reaction (F). Different reaction conditions were tested in both reactions, in Scheme 5 the optimized conditions are shown. The yields were fairly low in the coupling reactions, which may be due to the steric hindrance.

\subsection{Structure elucidation and characterization of} $(S, S)-1$ by NMR spectroscopy

Because of the complexity of the end product, and because our aim was to achieve full confidence in its structure, the constitution of $(S, S)$-1 was confirmed using one-dimensional $\left({ }^{1} \mathrm{H},{ }^{13} \mathrm{C}\left\{{ }^{1} \mathrm{H}\right\}\right.$, and $\left.{ }^{31} \mathrm{P}\left\{{ }^{1} \mathrm{H}\right\}\right)$ and a number of two-dimensional NMR spectra. The latter consisted of homonuclear $\left({ }^{1} \mathrm{H}-{ }^{1} \mathrm{H}\right)$ correlation spectroscopy (COSY; proton-proton scalar coupling through chemical bonds) and nuclear Overhauser effect spectroscopy (NOESY; proton-proton proximities in space), and heteronuclear $\left({ }^{1} \mathrm{H}-{ }^{13} \mathrm{C}\right)$ single quantum coherence (HSQC; one-bond proton-carbon correlations) and multiple bond connectivity (HMBC; two or three-bond, occasionally four-bond proton-carbon correlations) measurements.

The ${ }^{1} \mathrm{H}$ and ${ }^{13} \mathrm{C}$ NMR spectra of $(S, S)-\mathbf{1}$ exhibited crowded domains of resonances, making the structure elucidation

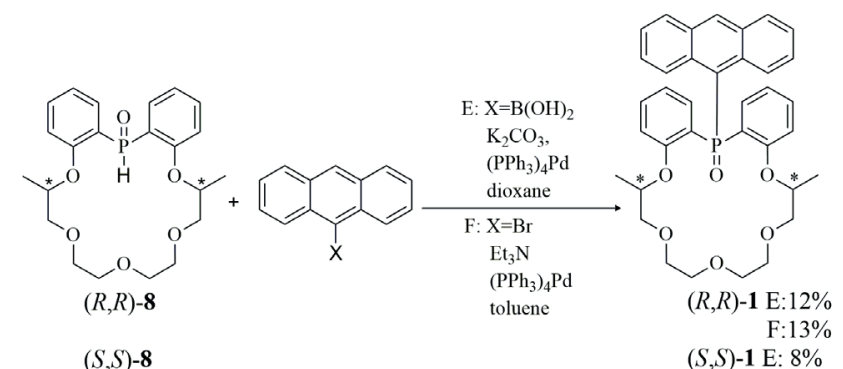

Scheme 5 Phosphorus-carbon coupling with boronic acid reagent or by the Hirao reaction

and spectral assignment a non-trivial process. Note in that regard that due to the phosphorus atom being a prochiral center, there is a diastereotopic relationship between the two "halves" [the corresponding groups are numbered as (a1-a6, b1-b5) and (a7-a12, b6-b10)] of the crown ether, as a result of which every atom has a different chemical shift. However the ${ }^{1} \mathrm{H}$ and ${ }^{13} \mathrm{C}$ signals of all $\mathrm{OCH}$ and $\mathrm{OCH}_{2}$ groups were found in a relatively narrow range of chemical shifts (8 peaks between 69 and 74 ppm in the ${ }^{13} \mathrm{C}$ NMR spectrum). Because the hindered rotation of the anthracene moiety is slow on the chemical shift timescale under the current experimental conditions, the signals of all aromatic proton and carbon atoms in the two benzene rings a14-a19 and a21-26 had different chemical shifts. As a result, 20 carbon resonances were found between 123 and 137 ppm, the majority of them being a doublet due to spin-spin coupling to the ${ }^{31} \mathrm{P}$ atom. In addition, quaternary aromatic carbon atoms adjacent to the phosphorus atom gave broad and barely detectable signals in the ${ }^{13} \mathrm{C}$ NMR spectrum; their presence was confirmed by ${ }^{1} \mathrm{H}^{-13} \mathrm{C}$ HMBC correlations.

To be able to give a full ${ }^{1} \mathrm{H}$ and ${ }^{13} \mathrm{C}$ NMR characterization (and subsequently, to verify the constitution of $(S, S)-\mathbf{1})$, we acquired the HSQC and the HMBC spectra with such a high resolution in the ${ }^{13} \mathrm{C}$ dimension which is uncommon in routine NMR applications. For the HSQC spectrum, 4096 increments were recorded, resulting in a $0.08 \mathrm{ppm} /$ row $\left({ }^{13} \mathrm{C}\right)$ resolution. For the HMBC spectrum, 2048 increments were used ( $0.17 \mathrm{ppm} / \mathrm{row})$.

Section 2.3 describes the most important (Fig. 2) correlations used during the structure elucidation of $(S, S)-\mathbf{1}$, which were supplemented by numerous other correlations found in the 2D NMR spectra.

Skeletal carbon-carbon connectivities between the proton-bearing carbons (a1-a2-a3-a4, a9-a10-a11-a12, a15a16-a17-a18, a22-a23-a24-a25, b2-b1-b3, b4-b5, b6-b7, and b8-b9-b10) were established from COSY cross peaks (a9-a10-a11-a12, a15-a16, a23-a24, and b6-b7), or when the 


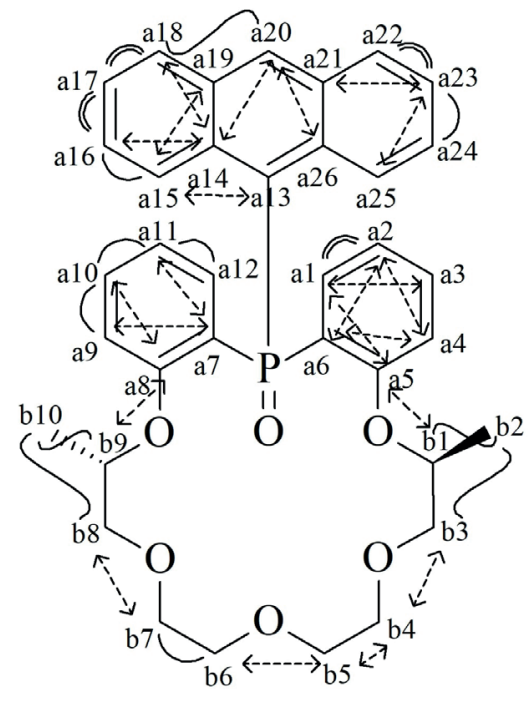

Fig. 2 Graphical representation of 2D NMR correlations validating the structure of crown ether $(S, S)$-1; COSY: curves, HSQC-COSY: double curves, NOESY: „S”-shaped curves, HMBC: dashed arrows

positions of the cross peaks were ambiguous, from HSQCCOSY artifacts $\left({ }^{3} J_{\mathrm{HH}}+{ }^{1} J_{\mathrm{CH}}\right)$ in the HSQC spectrum (a1a2, a16-a17-a18, a22-a23), and were further supplemented by HMBC $(\mathrm{a} 1 \rightarrow \mathrm{a} 3, \mathrm{a} 2 \rightarrow \mathrm{a} 4, \mathrm{a} 23 \rightarrow \mathrm{a} 25$, and $\mathrm{b} 4 \rightarrow \mathrm{b} 5)$ and NOESY (b2 $\rightarrow \mathrm{b} 1, \mathrm{~b} 2 \rightarrow \mathrm{b} 3, \mathrm{~b} 10 \rightarrow \mathrm{b} 8$, and b10 $\rightarrow \mathrm{b} 9$ ) correlations (Fig. 2). The position of the isolated $=\mathrm{CH}-$ group (a20) was evident from the NOESY spectrum (a18 $\rightarrow \mathrm{a} 20$ ).

Connections through oxygen atoms in the crown ether part of the molecule were confirmed by C-O-C-H three-bond HMBCs $(\mathrm{a} 5 \rightarrow \mathrm{b} 1, \mathrm{~b} 3 \rightarrow \mathrm{b} 4, \mathrm{~b} 5 \rightarrow \mathrm{b} 6, \mathrm{~b} 7 \rightarrow \mathrm{b} 8$, and $\mathrm{b} 9 \rightarrow \mathrm{a} 8)$.

The resonances due to the quaternary carbon atoms in the aromatic rings were assigned using the following ${ }^{3} J_{\mathrm{CH}}$ HMBC correlations: $(\mathrm{a} 5 \rightarrow \mathrm{a} 1),(\mathrm{a} 6 \rightarrow \mathrm{a} 2$ and $\mathrm{a} 4),(\mathrm{a} 7 \rightarrow \mathrm{a} 9$ and a11), (a $8 \rightarrow \mathrm{a} 10),(\mathrm{a} 13 \rightarrow \mathrm{a} 15),(\mathrm{a} 14 \rightarrow \mathrm{a} 16, \mathrm{a} 18$ and $\mathrm{a} 20)$, $(\mathrm{a} 19 \rightarrow \mathrm{a} 15),(\mathrm{a} 21 \rightarrow \mathrm{a} 23)$, and $(\mathrm{a} 26 \rightarrow \mathrm{a} 20)$ supported by other ${ }^{2} J_{\mathrm{CH}}$ and ${ }^{4} J_{\mathrm{CH}} \mathrm{HMBC}$ correlations.

Finally, the three aromatic rings were connected to the phosphorus atom through the carbon atoms for which we found a $\approx 100 \mathrm{~Hz}$ one-bond phosphorus-carbon spin-spin coupling constant. The full NMR assignment of $(S, S)-\mathbf{1}$ is given in Table 1.

\subsection{Complexation studies}

Studies on the enantiomeric differentation abilities of the new fluorescent chemosensors $(R, R)-\mathbf{1}$ and $(S, S)$-1 toward the enantiomers of protonated chiral primary amines and amino acid esters (PEA, 1-NEA, PGME, PAME) were performed in acetonitrile using UV-Vis and fluorescence spectroscopies. The absorption spectra of the macrocycles $(R, R)-\mathbf{1}$ and $(S, S)-\mathbf{1}$ showed slight spectral changes
Table 1 NMR spectroscopic data of $(S, S)$-1 in tetrachloroethane-d

\begin{tabular}{|c|c|c|}
\hline Group & $\begin{array}{c}{ }^{1} \mathrm{H} \text { NMR } \\
\delta_{\mathrm{H}}(\mathrm{ppm}) \\
\text { multiplicity }\end{array}$ & $\begin{array}{c}{ }^{13} \mathrm{C}\left\{{ }^{1} \mathrm{H}\right\} \mathrm{NMR} \\
\delta_{\mathrm{C}}(\mathrm{ppm})\end{array}$ \\
\hline a1 $(\mathrm{CH})$ & $\begin{array}{c}7.91 \mathrm{br} \mathrm{dd} ;{ }^{3} J_{\mathrm{PH}}=13.3 \mathrm{~Hz} \\
{ }^{3} J_{\mathrm{HH}}=7.2 \mathrm{~Hz}\end{array}$ & $134.96 \mathrm{~d} ;{ }^{2} J_{\mathrm{PC}}=8.1 \mathrm{~Hz}$ \\
\hline a2 (CH) & $7.02 \mathrm{~m}$ & $120.17 \mathrm{~d} ;{ }^{3} J_{\mathrm{PC}}=12.1 \mathrm{~Hz}$ \\
\hline a3 $(\mathrm{CH})$ & $7.51 \mathrm{~m}$ & $133.20 \mathrm{~d} ;{ }^{4} J_{\mathrm{PC}}=1.8 \mathrm{~Hz}$ \\
\hline a4 $(\mathrm{CH})$ & $7.01 \mathrm{~m}$ & $112.28 \mathrm{~d} ;{ }^{3} J_{\mathrm{PC}}=6.0 \mathrm{~Hz}$ \\
\hline a5 (C) & - & $158.84 \mathrm{~s}$ \\
\hline a6 (C) & - & $\begin{array}{l}\approx 123.7 \mathrm{br} \mathrm{d} \\
{ }^{1} J_{\mathrm{PC}} \approx 105 \mathrm{~Hz}\end{array}$ \\
\hline a7 (C) & - & $\begin{array}{l}\approx 124.7 \mathrm{brd} \\
{ }^{1} J_{\mathrm{PC}} \approx 111 \mathrm{~Hz}\end{array}$ \\
\hline a8 (C) & - & $160.05 \mathrm{~s}$ \\
\hline a9 (CH) & $\begin{array}{c}6.95 \mathrm{dd} ; \\
{ }^{3} J_{\mathrm{HH}}=8.1 \mathrm{~Hz},{ }^{4} J_{\mathrm{PH}}=5.4 \mathrm{~Hz}\end{array}$ & $\begin{array}{c}113.08 \mathrm{~d} \\
{ }^{3} J_{\mathrm{PC}}=6.9 \mathrm{~Hz}\end{array}$ \\
\hline a10 (CH) & $7.32 \mathrm{~m}$ & $132.37 ;{ }^{4} J_{\mathrm{PC}}=1.9 \mathrm{~Hz}$ \\
\hline a11 $(\mathrm{CH})$ & $6.71 \mathrm{~m}$ & $118.86 \mathrm{~d} ;{ }^{3} J_{\mathrm{PC}}=12.5 \mathrm{~Hz}$ \\
\hline a12 (CH) & $7.07 \mathrm{~m}$ & $135.23 \mathrm{~d} ;{ }^{2} J_{\mathrm{PC}}=8.9 \mathrm{~Hz}$ \\
\hline a13 (C) & - & $\approx 124.2 \mathrm{br} \mathrm{d} ;{ }^{1} J_{\mathrm{PC}} \approx 104 \mathrm{~Hz}$ \\
\hline a14 (C) & - & $136.42 \mathrm{~d} ;{ }^{2} J_{\mathrm{PC}}=7.4 \mathrm{~Hz}$ \\
\hline a15 (CH) & $9.71 \mathrm{brd} ;{ }^{3} J_{\mathrm{HH}}=9.0 \mathrm{~Hz}$ & $\approx 128.87 \mathrm{br} \mathrm{d} ;{ }^{3} J_{\mathrm{PC}} \approx 7 \mathrm{~Hz}$ \\
\hline a16 (CH) & $7.46 \mathrm{~m}$ & $125.97 \mathrm{~s}$ \\
\hline a17 (CH) & $7.51 \mathrm{~m}$ & $125.10 \mathrm{~s}$ \\
\hline a18 (CH) & $8.07 \mathrm{br} \mathrm{d} ;{ }^{3} J_{\mathrm{HН}}=8.4 \mathrm{~Hz}$ & $128.77 \mathrm{~s}$ \\
\hline a19 (C) & - & $131.26 \mathrm{~d} ;{ }^{3} J_{\mathrm{PC}}=10.8 \mathrm{~Hz}$ \\
\hline a20 (CH) & $8.66 \mathrm{br} \mathrm{s}$ & $133.13 \mathrm{~d} ;{ }^{4} J_{\mathrm{PC}}=3.4 \mathrm{~Hz}$ \\
\hline $\mathrm{a} 21(\mathrm{C})$ & - & $130.59 \mathrm{~d} ;{ }^{3} J_{\mathrm{PC}}=11.2 \mathrm{~Hz}$ \\
\hline a22 (CH) & $7.99 \mathrm{~m}$ & $128.90 \mathrm{~s}$ \\
\hline a23 (CH) & $7.34 \mathrm{~m}$ & $124.47 \mathrm{~s}$ \\
\hline a24 (CH) & $7.06 \mathrm{~m}$ & $125.26 \mathrm{~s}$ \\
\hline a25 (CH) & $7.98 \mathrm{~m}$ & $126.62 \mathrm{~d} ;{ }^{3} J_{\mathrm{PC}}=7.8 \mathrm{~Hz}$ \\
\hline a26 (C) & - & $\begin{array}{c}132.80 \mathrm{~d} \\
{ }^{2} J_{\mathrm{PC}}=9.3 \mathrm{~Hz}\end{array}$ \\
\hline b1 $(\mathrm{CH})$ & $4.47 \mathrm{~m}$ & $72.31 \mathrm{~s}$ \\
\hline b2 $\left(\mathrm{CH}_{3}\right)$ & $0.60 \mathrm{brd} ;{ }^{3} J_{\mathrm{HH}} \approx 6 \mathrm{~Hz}$ & $15.58 \mathrm{~s}$ \\
\hline b3 $\left(\mathrm{CH}_{2}\right)$ & $\begin{array}{l}2.90 \mathrm{dd} ;{ }^{2} J_{\mathrm{HH}}=10.5 ; \\
{ }^{3} J_{\mathrm{HH}}=6.2 \mathrm{~Hz} ; 3.05 \mathrm{~m}\end{array}$ & $74.04 \mathrm{~s}$ \\
\hline b4 $\left(\mathrm{CH}_{2}\right)$ & $3.20 \mathrm{~m} ; 3.30 \mathrm{~m}$ & $70.56 \mathrm{~s}$ \\
\hline b5 $\left(\mathrm{CH}_{2}\right)$ & $3.39 \mathrm{~m} ; 3.44 \mathrm{~m}$ & $69.78 \mathrm{~s}$ \\
\hline b6 $\left(\mathrm{CH}_{2}\right)$ & $3.41 \mathrm{~m} ; 3.54 \mathrm{~m}$ & $70.46 \mathrm{~s}$ \\
\hline b7 $\left(\mathrm{CH}_{2}\right)$ & $3.50 \mathrm{~m} ; 3.54 \mathrm{~m}$ & $70.52 \mathrm{~s}$ \\
\hline $\mathrm{b} 8\left(\mathrm{CH}_{2}\right)$ & $\begin{array}{c}2.74 \mathrm{dd} ;{ }^{2} J_{\mathrm{HH}}=10.3 \mathrm{~Hz}, \\
{ }^{3} J_{\mathrm{HH}}=5.1 \mathrm{~Hz} ; 3.12 \mathrm{dd} ; \\
{ }^{2} J_{\mathrm{HH}}=10.3 \mathrm{~Hz},{ }^{3} J_{\mathrm{HH}}=6.2 \mathrm{~Hz}\end{array}$ & $73.26 \mathrm{~s}$ \\
\hline b9 $(\mathrm{CH})$ & $4.48 \mathrm{~m}$ & $72.66 \mathrm{~s}$ \\
\hline $\mathrm{b} 10\left(\mathrm{CH}_{3}\right)$ & $0.72 \mathrm{br} \mathrm{d} ;{ }^{3} J_{\mathrm{HH}} \approx 6 \mathrm{~Hz}$ & $16.51 \mathrm{~s}$ \\
\hline${ }^{31} \mathrm{P}$ & $\delta_{\mathrm{P}}=26.4 \mathrm{ppm}(\mathrm{br})$ & \\
\hline
\end{tabular}


upon titration with the enantiomers of the primary ammonium salts (Fig. 3A). However, during the addition of the guests a significant decrease could be observed in the fluorescence emission spectra, which means that the fluorescence was quenched in the complexes (Fig. 3B). We constructed the Stern-Volmer plots at $438 \mathrm{~nm}$, which showed a clear downward curvature for each examined amine. A typical example of this is shown in Fig. 3C for the enantiomers of PGME. In this case, the calculation of the complex stability constants is much more difficult [25]. All the fluorescence spectral changes were evaluated using global nonlinear regression analysis, and the stability constants (Table 2) as well as the degrees of enantiomeric differentiation were calculated.

The results in Table 2 show that despite the fact that macrocycles $(R, R) \mathbf{- 1}$ and $(S, S)-\mathbf{1}$ form termodinamically stable complexes with chiral ammonium cations, the macrocycles revealed moderate enantiomeric differentiation abilities toward the enantiomers of PEA, 1-NEA, PGME and PAME. The strongest binding by the macrocycles was observed in the case of PGME. This observation is similar to the results of our previous study, in which we examined the transport abilities of crown ethers containing a diarylphosphinic acid unit in an aqueous source phase/
Table 2 Stability constants for complexes $(R, R)-\mathbf{1}$ and $(S, S) \mathbf{- 1}$ with the enantiomers of chiral primary ammonium salts $(\log K)$ and the degrees of enantiomeric recognition $(\Delta \log K)$

\begin{tabular}{lcccccc}
\hline & \multicolumn{3}{c}{$(R, R)-\mathbf{1}$} & \multicolumn{3}{c}{$(S, S)-\mathbf{1}$} \\
\cline { 2 - 7 } & $\log K(R)$ & $\log K(S)$ & $\Delta \log K$ & $\log K(R)$ & $\log K(S)$ & $\Delta \log K$ \\
\hline PEA & 3.97 & 4.03 & -0.06 & 4.12 & 4.01 & +0.11 \\
1-NEA & 4.29 & 4.37 & -0.08 & 4.21 & 4.14 & +0.07 \\
PGME & 4.43 & 4.28 & +0.15 & 4.26 & 4.36 & -0.10 \\
PAME & 3.99 & 3.82 & +0.17 & 3.99 & 4.10 & -0.11 \\
\hline
\end{tabular}

lipophilic organic bulk liquid membrane/aqueous receiving phase system. These macrocycles transported phenylglycinol faster and with a higher enantioselectivity than phenylethyamine and phenylalaninol [26].

\section{Conclusions}

The synthesis of the $(R, R)$ and $(S, S)$ enantiomers of a new fluorescent monophospha-crown ether $\mathbf{1}$ has been performed. The constitution of $(S, S)-\mathbf{1}$ was confirmed using one-dimensional $\left({ }^{1} \mathrm{H},{ }^{13} \mathrm{C}\left\{{ }^{1} \mathrm{H}\right\}\right.$, and $\left.{ }^{31} \mathrm{P}\left\{{ }^{1} \mathrm{H}\right\}\right)$ and two-dimensional NMR spectra. The complex formation of the chiral ligands with the enantiomers of PEA, 1-NEA, PGME, and PAME was studied by fluorescence spectroscopy using acetonitrile as a solvent. The newly achieved
$\mathbf{A}$

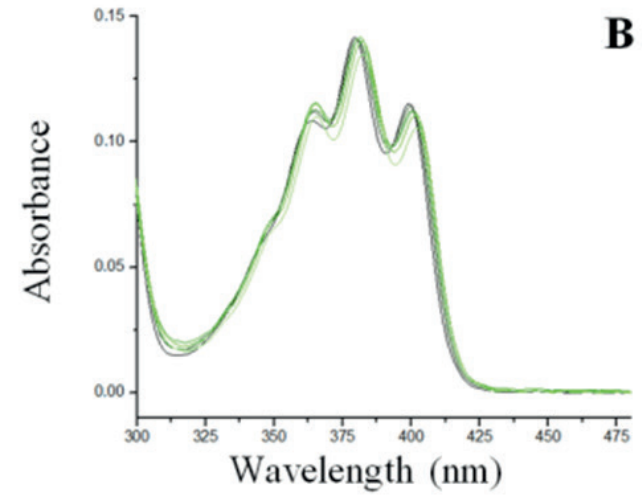

B

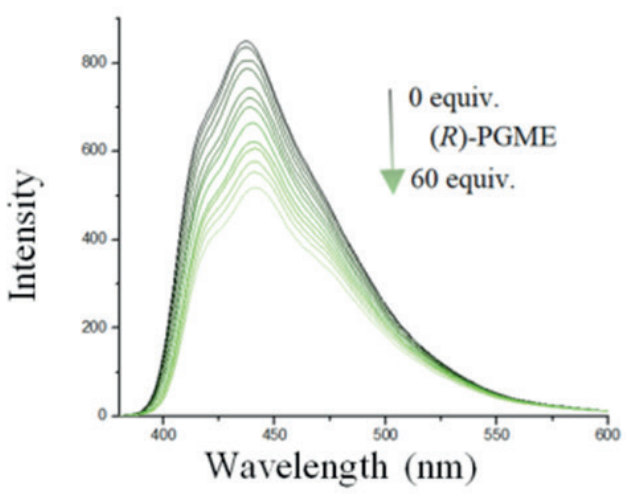

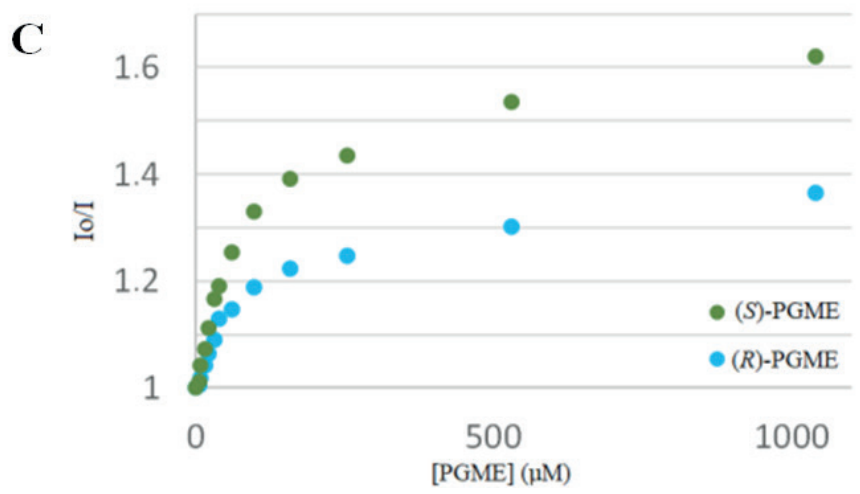

Fig. 3 Series of absorption spectra upon titration of $(R, R)-1$ with $(R)$-PGME (A), series of fluorescence spectra upon titration of $(R, R)$-1 with $(R)$-PGME (B), Stern-Volmer plots for quenching of $(R, R)$-1 by addition of $(R)$ - and $(S)$-PGME $(\mathrm{C})$ 
macrocycles showed moderate enantiomeric recognition ability, but this can be improved presumably by modifications of the structures of the fluorescent ligands.

\section{Experimental}

\subsection{General}

All reagents were purchased from Sigma-Aldrich Corporation unless otherwise noted. Compounds $(S, S)$-2 [14], $(R, R)-6$ [16], 5 [19] were prepared as reported in the respective literature. The progress of all reactions was monitored by TLC and visualized by UV lamp (254 nm). Silica gel 60 F254 (Merck) plates were used for TLC. Silica gel 60 PF254 (Merck) plates were used for preparative TLC. Silica gel 60 (70-230 mesh, Merck) were used for column chromatography. Ratios of solvents for the eluents are given in volumes $(\mathrm{mL} / \mathrm{mL})$. Solvents were dried and purified according to well established methods [27]. Evaporations were carried out under reduced pressure. Melting points were taken on a Boetius micro-melting point apparatus and are uncorrected. Optical rotations were taken on a Perkin-Elmer 241 polarimeter that was calibrated by measuring the optical rotations of both enantiomers of menthol. Infrared (IR) spectra were recorded on a Bruker Alpha-T FT-IR spectrometer. In the case of $(S, S)$-1 one-dimensional ${ }^{1} \mathrm{H}$ and ${ }^{13} \mathrm{C}$ NMR spectra, as well as two-dimensional ${ }^{1} \mathrm{H}-{ }^{1} \mathrm{H}$ COSY, ${ }^{1} \mathrm{H}-{ }^{1} \mathrm{H}$ NOESY, ${ }^{1} \mathrm{H}-{ }^{13} \mathrm{C}$ HSQC, and ${ }^{1} \mathrm{H}-{ }^{13} \mathrm{C}$ HMBC spectra were recorded on a Burker Avance III HDX 500 MHz NMR spectrometer equipped with a ${ }^{1} \mathrm{H}\left\{{ }^{13} \mathrm{C} /{ }^{15} \mathrm{~N}\right\}$ $5 \mathrm{~mm}$ TCI CryoProbe $\left({ }^{1} \mathrm{H}: 499.9 \mathrm{MHz},{ }^{13} \mathrm{C}\right.$ : $\left.125.7 \mathrm{MHz}\right)$ (Bruker Corporation, Billerica, MA, USA). ${ }^{31} \mathrm{P}$ NMR measurements were performed on a Burker Avance III HDX $400 \mathrm{MHz}$ NMR spectrometer equipped with a ${ }^{15} \mathrm{~N}-{ }^{31} \mathrm{P}\left\{{ }^{1} \mathrm{H}\right\}$ $5 \mathrm{~mm}$ CryoProbe Prodigy $\left({ }^{31} \mathrm{P}: 161.8 \mathrm{MHz}\right)$. In all other cases ${ }^{1} \mathrm{H}(500 \mathrm{MHz})$ and ${ }^{13} \mathrm{C}(125 \mathrm{MHz})$ NMR spectra were obtained on a Bruker DRX-500 Avance spectrometer. ${ }^{1} \mathrm{H}$ $(300 \mathrm{MHz})$ and ${ }^{13} \mathrm{C}(75.5 \mathrm{MHz}) \mathrm{NMR}$ spectra were taken on a Bruker 300 Avance spectrometer. ${ }^{31} \mathrm{P}(121.5 \mathrm{MHz}$, reference: $\mathrm{H}_{3} \mathrm{PO}_{4}$ ) NMR spectra were recorded on a Brucker 300 Avance spectrometer. Mass spectra (LC-MS) were recorded on an Agilent 1200 Series coupled Agilent 6130 Series Quadrupole spectrometer system in electrospray ionization (ESI) mode using water $\left(1 \% \mathrm{NH}_{4} \mathrm{HCO}_{3}\right) /$ acetonitrile ( $8 \%$ water, $1 \% \mathrm{NH}_{4} \mathrm{HCO}_{3}$ ) as an eluent in gradient elution $\left(5-100 \%\right.$ acetonitrile, $\left.0.6 \mathrm{~mL} / \mathrm{min}, 40^{\circ} \mathrm{C}\right)$ on a Phenomenex Gemini NX-C18 column $(3 \mu \mathrm{m}, 110 \AA$, 150 $\times 3.0 \mathrm{~mm}$ ). HRMS analyses were performed on a Thermo Velos Pro Orbitrap Elite (Thermo Fisher Scientific,
Bremen, Germany) system. The ionization method was ESI and was operated in positive ion mode. The protonated molecular ion peaks were fragmented by CID at a normalized collision energy of $35 \%$. The samples were dissolved in methanol. Data acquisition and analysis were accomplished with Xcalibur software version 2.2 (Thermo Fisher Scientific). UV-vis spectra were taken on a Unicam UV4-100 spectrophotometer. Quartz cuvettes with a path length of $1 \mathrm{~cm}$ were used. Fluorescence emission spectra were recorded on a Perkin-Elmer LS 50B luminescent spectrometer and were corrected by the spectrometer software. Quartz cuvettes with path length of $1 \mathrm{~cm}$ were used. The enantiomers of PEA, 1-NEA, PGME, and PAME were prepared in our laboratory [28]. The concentrations of sensor molecules were $0.2,2$ or $20 \mu \mathrm{M}$ during the fluorescence titrations. Stability constants of the complexes were determined by global nonlinear regression analysis using Origin Pro 8.6 software. The following user defined fitting function was used:

$$
F=F_{0}-\left(F_{0}-F_{c}\right) \cdot \frac{[H]_{t}+[L]_{a}+\frac{1}{K_{a}}-\sqrt{\left([H]_{t}+[L]_{a}+\frac{1}{K_{a}}\right)^{2}-4 \cdot[H]_{t} \cdot[L]_{a}}}{2 \cdot[H]_{t}}
$$

where $F$ is the measured fluorescence, $F_{0}$ the starting fluorescence, $F_{C}$ the residual fluorescence of the complex, $K_{a}$ the dissociation constant, $[H]_{t}$ the concentration of the crown ether, $[L]_{a}$ the concentration of the added ligand [25].

\section{2 (1R, 11R)-3,6,9-Trioxatridecane-1,11-diol [ $(R, R)-4]$}

$(R)$-Propylene oxide $((R)-\mathbf{3})$ was prepared from racemic propylene oxide by the procedure of Jacobsen [18]. The tetraethylene glycol derivative $(R, R)-\mathbf{4}$ was prepared in the same way as described for its enantiomer $(S, S)-\mathbf{4}$ [15] starting from $(R)$-propylene oxide $((R)-3)(10.1 \mathrm{~mL}$, $0.144 \mathrm{~mol})$. The crude product was purified by chromatography on silica gel using acetone-hexane (1:4) as eluent to obtain $(R, R)-4$ as a colorless oil $(8.16 \mathrm{~g}, 51 \%)$. $[\alpha]_{D}^{25}=-42.5$ (c $0.74 \mathrm{CH}_{2} \mathrm{Cl}_{2}$ ). The product had the same further physical properties and spectroscopic data as its enantiomer $(S, S)-\mathbf{4}$ reported in the literature [15].

\section{$4.3(1 R, 11 R)-3,6,9-T r i o x a t r i d e c a n e-1,11-d i-4-$ methylbenzene-sulfonate $[(\boldsymbol{R}, \boldsymbol{R})-2]$}

Tosyl chloride $(27.0 \mathrm{~g}, 0.142 \mathrm{~mol})$ and pyridine $(30 \mathrm{~mL})$ were placed under Ar in a three necked flask fitted with a stirring bar and dropping funnel. The mixture was cooled to $0{ }^{\circ} \mathrm{C}$, and $(R, R)-4(7.0 \mathrm{~g}, 31.5 \mathrm{mmol})$ dissolved in pyridine $(30 \mathrm{~mL})$ was added dropwise. After addition, 
the mixture was allowed to warm up to room temperature. The mixture was stirred for two days, and then the pyridine was removed. The residue was dissolved in a mixture of $10 \%$ aqueous $\mathrm{HCl}$ solution $(50 \mathrm{~mL})$ and dichloromethane $(50 \mathrm{~mL})$. The phases were shaken thoroughly, and then separated. The aqueous phase was shaken three times with $40 \mathrm{~mL}$ portions of dichloromethane. The combined organic phase was dried over anhydrous $\mathrm{MgSO}_{4}$, filtered and the solvent was removed. The crude product was purified by column chromatography on silica gel using ethyl acetate: hexane (1:2) as eluent to obtain $(R, R)-2(14.05 \mathrm{~g}, 84 \%)$ as a pale yellow oil. $[\alpha]_{D}^{25}=+3.12\left(\mathrm{c} 1.1 \mathrm{CH}_{2} \mathrm{Cl}_{2}\right)$. The product had the same further physical properties and spectroscopic data as its enantiomer $(S, S)$-2 reported in the literature [16].

\section{$4.4(6 S, 16 S)-22-$ Ethoxy-6,16-dimethyl-}

\section{$6,7,9,10,12,13,15,16$-octahydro-22H-22 $\lambda^{5}$-dibenzo[n,q]} $[1,4,7,10,13,16]$ pentaoxaphosphacyclooctadecin-22-one $[(S, S)-6]$

Macrocycle $(S, S)$-6 was prepared in the same way as described for its enantiomer $(R, R)-6$ [16] starting from ditosylate $(R, R)-2(3.0 \mathrm{~g}, 5.65 \mathrm{mmol})$ and phosphinate $5(1.63 \mathrm{~g}$, $5.85 \mathrm{mmol})$. $[\alpha]_{D}^{25}=+29.4\left(\mathrm{c} 1.0 \mathrm{CH}_{2} \mathrm{Cl}_{2}\right)$. The product had the same further physical properties and spectroscopic data as its enantiomer $(R, R)-6$ reported in the literature [16].

\section{5 (6R,16R)-6,16-Dimethyl-6,7,9,10,12,13,15,16- octahydro-22H-22 $\lambda^{5}$-dibenzo $[n, q][1,4,7,10,13,16]$ pentaoxaphosphacyclooctadecin-22-one $[(R, R)-8]$ Procedure $C$}

A solution of macrocycle $(R, R)-6(120 \mathrm{mg}, 0.26 \mathrm{mmol})$ in $5 \mathrm{~mL}$ abs. toluene and $5 \mathrm{~mL}$ abs. tetrahydrofuran was placed under Ar in a three-necked flask fitted with a stirring bar and dropping funnel. The solution was cooled to $0{ }^{\circ} \mathrm{C}$, and $70 \%$ solution of bis(2-methoxyethoxy)aluminum hydride $(200 \mathrm{mg}, 0.69 \mathrm{mmol})$ in toluene with $5 \mathrm{~mL}$ abs. tetrahydrofuran was added to the reaction mixture. It was stirred for one hour at $0{ }^{\circ} \mathrm{C}$ and for three hours at room temperature, and then $20 \%$ aqueous $\mathrm{HCl}(1.5 \mathrm{~mL})$ was added. The reaction mixture was filtered, and the filtrate was evaporated. The residue was taken up in water $(30 \mathrm{~mL})$ and dichloromethane $(30 \mathrm{~mL})$. The phases were shaken thoroughly, and then they were separated. The aqueous phase was shaken three times with $20 \mathrm{~mL}$ portions of dichloromethane. The combined organic phase was dried over anhydrous $\mathrm{MgSO}_{4}$, filtered and the solvent was removed. The crude product was purified by PLC on silica gel using dichloromethane: methanol (30:1) as eluent to get $(R, R)-8(21 \mathrm{mg}, 19 \%)$ as a colorless oil. $\mathrm{R}_{\mathrm{f}}=0.36$ (silica TLC, 1:20 dichloromethane-methanol); IR $(\mathrm{KBR}) v_{\max }=3381,2976,2932,2905,2869,1589,1577$, $1473,1444,1378,1353,1279,1243,1172,1135,1111$, 1090, 1040, 984, 939, 924, 892, 790, 757, 705, 606, 554, 543, $491 \mathrm{~cm}^{-1} ;[\alpha]_{D}^{30}=-17.7\left(\mathrm{c} 1.0 \mathrm{CH}_{2} \mathrm{Cl}_{2}\right) ;{ }^{1} \mathrm{H}-\mathrm{NMR}(500$ $\left.\mathrm{MHz}, \mathrm{CD}_{3} \mathrm{CN}\right): \delta 0.94\left(\mathrm{~d}, J=6 \mathrm{~Hz}, 3 \mathrm{H}, \mathrm{CH}_{3}\right), 1.28$ (d, $\left.J=6 \mathrm{~Hz}, 3 \mathrm{H}, \mathrm{CH}_{3}\right), 3.03-3.06\left(\mathrm{~m}, 1 \mathrm{H}, \mathrm{OCH}_{2}\right), 3.18-3.22$ $\left(\mathrm{m}, 1 \mathrm{H}, \mathrm{OCH}_{2}\right), 2.26-2.28\left(\mathrm{~m}, 2 \mathrm{H}, \mathrm{OCH}_{2}\right), 3.36-3.55(\mathrm{~m}$, $\left.8 \mathrm{H}, \mathrm{OCH}_{2}\right), 4.54-4.60(\mathrm{~m}, 1 \mathrm{H}, \mathrm{OCH}), 4.70-4.75(\mathrm{~m}, 1 \mathrm{H}$, OCH), 6.99-7.02 (m, 1H, Ar-H), 7.06-7.19 (m, 3H, Ar-H), 7.34-7.38 (m, 1H, Ar-H), 7.50-7.60 (m, 2H, Ar-H), 7.83-7.87 (m, 1H, Ar-H), 8.16 (d, $J=512 \mathrm{~Hz}, 1 \mathrm{H}, \mathrm{PH}) \mathrm{ppm} ;{ }^{13} \mathrm{C}-\mathrm{NMR}$ $\left(300 \mathrm{MHz}, \mathrm{CD}_{3} \mathrm{CN}\right): \delta 15.78,16.19\left(\mathrm{CH}_{3}\right), 70.49,70.52$, 70.64, 70.68, 73.06, 73.41, 73.47, $73.92\left(\mathrm{OCH}, \mathrm{OCH}_{2}\right)$, 112.65 (d, $J=6 \mathrm{~Hz}, \mathrm{Ar}-\mathrm{H}), 112.90$ (d, $J=6 \mathrm{~Hz}, \mathrm{Ar}-\mathrm{H})$, 120.26 (d, $J=12 \mathrm{~Hz}, \mathrm{ArH}), 120.42$ (d, $J=105 \mathrm{~Hz}, \mathrm{Ar}-\mathrm{H})$, 120.54 (d, $J=13 \mathrm{~Hz}, \mathrm{Ar}-\mathrm{H}), 121.83$ (d, $J=106 \mathrm{~Hz}, \mathrm{Ar}-\mathrm{H})$, 132.53 (d, $J=7 \mathrm{~Hz}$, Ar-H), 133.51 (d, $J=2 \mathrm{~Hz}$, Ar-H), 133.88 (d, $J=2 \mathrm{~Hz}, \mathrm{Ar}-\mathrm{H}), 133.91$ (d, $J=7 \mathrm{~Hz}, \mathrm{Ar}-\mathrm{H}), 159.25$ (d, $J=$ $3 \mathrm{~Hz}, \mathrm{Ar}-\mathrm{H}), 159.52$ (d, $J=4 \mathrm{~Hz}, \mathrm{Ar}-\mathrm{H}) ;{ }^{31} \mathrm{P}-\mathrm{NMR}\left(\mathrm{CD}_{3} \mathrm{CN}\right.$, $121 \mathrm{MHz}): \delta$ 9.12; HRMS m/z $=421.17725(\mathrm{M}+\mathrm{H})^{+}(\mathrm{calcd}$ for $\mathrm{C}_{22} \mathrm{H}_{29} \mathrm{O}_{6} \mathrm{P}, 421.17745$ )

\section{Procedure D}

A solution of lithium aluminum hydride (134 mg, $3.53 \mathrm{mmol}$ ) in $8 \mathrm{~mL}$ abs. diethyl ether was placed under Ar in a threenecked flask fitted with a stirring bar and dropping funnel. The solution was cooled to $0{ }^{\circ} \mathrm{C}$, and a solution of $(R, R)-6$ (400 mg, $0.86 \mathrm{mmol}$ ) in $13 \mathrm{~mL}$ abs. toluene was added dropwise. After addition, the mixture was warmed up to $40{ }^{\circ} \mathrm{C}$ and stirred for 3 hours at this temperature. Thereafter the bright green reaction mixture was cooled down to $0{ }^{\circ} \mathrm{C}$, water was added dropwise $(25 \mathrm{~mL})$, then diethyl ether (35 mL). The phases were shaken thoroughly, and then separated. The separation was facilitated with tetramethyl-ammonium hydrogen-sulfate. The aqueous phase was shaken three times with $15 \mathrm{~mL}$ portions of diethyl ether. The combined organic phase was dried over anhydrous $\mathrm{MgSO}_{4}$, filtered and the solvent was removed. The crude product was purified by PLC on silica gel using dichloromethane: methanol (30:1) as eluent to get $(R, R)-8$ (261 mg, $72 \%)$, which had the same physical properties and spectroscopic data than the one described above in procedure $\mathrm{C}$. 
4.6 (6S,16S)-6,16-Dimethyl-6,7,9,10,12,13,15,16octahydro-22H-22 $\lambda^{5}$-dibenzo[ $\left.n, q\right][1,4,7,10,13,16]$ pentaoxaphosphacyclooctadecin -22-one $[(S, S)-8]$ Macrocycle $(S, S)-\mathbf{8}$ was prepared in the same way as described above for $(R, R)-\mathbf{8}$ (procedure D) starting from phosphinate $(S, S)-6$ (400 mg, $0.86 \mathrm{mmol})$. Yield: $246 \mathrm{mg}$ (68\%). $[\alpha]_{D}^{33}=+18.2\left(\right.$ c $0.74 \mathrm{CH}_{2} \mathrm{Cl}_{2}$ ). Other physical properties and spectroscopic data of $(S, S)-\mathbf{8}$ concurred with those of $(R, R)-\mathbf{8}$.

\section{$4.7(6 R, 16 R)-22$-(Anthracen-9-yl)-6,16-dimethyl- $6,7,9,10,12,13,15,16-o c t a h y d r o-22 H-22 \lambda^{5}$-dibenzo $[n, q]$ $[1,4,7,10,13,16]$ pentaoxaphosphacyclooctadecin-22-one $[(\boldsymbol{R}, \boldsymbol{R})-1]$}

\section{Procedure E}

Macrocycle $(R, R)-8$ (200 mg, $0.48 \mathrm{mmol})$, anthracene boronic acid (187 $\mathrm{mg}, 0.84 \mathrm{mmol})$ and $\mathrm{Pd}\left(\mathrm{PPh}_{3}\right)_{4}(58 \mathrm{mg}$, $0.05 \mathrm{mmol})$ were dissolved in dry dioxane $(15 \mathrm{~mL})$ and placed under Ar in a three necked flask fitted with a stirring bar. Thereafter finely powdered anhydrous $\mathrm{K}_{2} \mathrm{CO}_{3}$ (42 mg, $0.30 \mathrm{mmol}$ ) was added to the reaction mixture, and it was heated to $100{ }^{\circ} \mathrm{C}$ and stirred at this temperature for two days. The mixture was allowed to cool down to room temperature, and $\mathrm{CH}_{2} \mathrm{Cl}_{2}(30 \mathrm{~mL})$ and water $(30 \mathrm{~mL})$ were added. The phases were shaken well and separated. The aqueous phase was shaken with $\mathrm{CH}_{2} \mathrm{Cl}_{2}(3 \times 20 \mathrm{~mL})$. The combined organic phase was dried over $\mathrm{MgSO}_{4}$, filtered and the solvent was removed. The crude product was purified by PLC on silica gel first using chloroform: methanol (30:1) and then chloroform: acetonitrile: ethanol: methanol (10:10:1:1) as eluents to obtain $(R, R)-\mathbf{1}(37 \mathrm{mg}, 13 \%)$ as a yellow powder. $\mathrm{R}_{\mathrm{f}}=0.27$ (silica TLC, 1:20 dichloromethane-methanol); IR (KBR) $v_{\text {max }}=3375,3063,2973,2929,2869,1721,1620,1587,1573$, $1512,1472,1442,1376,1351,1280,1246,1171,1135,1104$, $1079,1042,943,895,820,786,754,738,686,604,563,552$, $524,500,439 \mathrm{~cm}-1 ;[\alpha]_{D}^{30}=-20.2\left(\mathrm{c} 0.5 \mathrm{CH}_{2} \mathrm{Cl}_{2}\right)$; HRMS m/z $=597.23972(\mathrm{M}+\mathrm{H})^{+}\left(\right.$calcd for $\left.\mathrm{C}_{36} \mathrm{H}_{38} \mathrm{O}_{6} \mathrm{P}, 597.24005\right)$

\section{References}

[1] Hunter, C. A., Sanders, J. K. M. "The nature of $\pi-\pi$ interctions", Journal of the American Chemical Society, 112(14), pp. 55255534, 1990.

https://doi.org/10.1021/ja00170a016

[2] Anslyn, E. V., Dougherty, D. A. "Modern physical organic chemistry", University Science Books, Sausalito, California, USA, 2005.

[3] Mahadevi, A. S., Sastry, G. N. "Cation- $\pi$ Interaction: Its Role and Relevance in Chemistry, Biology, and Material Science", Chemical Reviews, 113(3), pp. 2100-2138, 2013.

https://doi.org/10.1021/cr300222d

\section{Procedure F}

$\operatorname{Macrocycle}(R, R)-8(60 \mathrm{mg}, 0.14 \mathrm{mmol}), 9$-bromoanthracene (55 mg, $0.22 \mathrm{mmol})$ and $\mathrm{Pd}\left(\mathrm{PPh}_{3}\right)_{4}(17 \mathrm{mg}, 0.02 \mathrm{mmol})$ were dissolved in dry toluene $(5 \mathrm{~mL})$ and placed under $\mathrm{Ar}$ in a three-necked flask fitted with a stirring bar. Thereafter $\mathrm{Et}_{3} \mathrm{~N}(32 \mu \mathrm{L}, 0.22 \mathrm{mmol})$ was added to the reaction mixture, and it was heated to $100{ }^{\circ} \mathrm{C}$ and stirred at this temperature for two days. The mixture was allowed to cool down to room temperature, and $\mathrm{CH}_{2} \mathrm{Cl}_{2}(10 \mathrm{~mL})$ and water $(10 \mathrm{~mL})$ were added. The phases were shaken well and separated. The aqueous phase was shaken with $\mathrm{CH}_{2} \mathrm{Cl}_{2}$ $(3 \times 5 \mathrm{~mL})$. The combined organic phase was dried over $\mathrm{MgSO}_{4}$, filtered and the solvent was removed. The crude product was purified by PLC on silica gel first using chloroform: methanol $(25: 1)$ and then dichlorometane: methanol (30:1) as eluents to obtain $(R, R)-\mathbf{1}(8 \mathrm{mg}, 9 \%)$, which had the same physical properties and spectroscopic data as the one described above in procedure $\mathrm{E}$.

\section{$4.8(6 S, 16 S)-22-($ Anthracen-9-yl)-6,16-dimethyl- $6,7,9,10,12,13,15,16-o c t a h y d r o-22 H-22 \lambda^{5}$-dibenzo $[n, q]$ $[1,4,7,10,13,16]$ pentaoxaphosphacyclooctadecin-22-one $[(S, S)-1]$}

Macrocycle $(S, S)$-1 was prepared in the same way as described above for $(R, R)-\mathbf{1}$ (procedure E) starting from secondary phosphine oxide $(S, S)-8$ (200 mg, $0.48 \mathrm{mmol})$. Yield: $34 \mathrm{mg}(12 \%)$. $[\alpha]_{D}^{33}=-20.2\left(\mathrm{c} 0.5 \mathrm{CH}_{2} \mathrm{Cl}_{2}\right)$. Other physical properties and spectroscopic data of $(S, S)$-1 concurred with those of $(R, R)-\mathbf{1}$.

\section{Acknowledgements}

Financial supports of the National Research, Development and Innovation Office (grant number: K128473) and the New Széchenyi Development Plan (TÁMOP-4.2.1/B-09/1/ KMR-2010-0002) are gratefully acknowledged. G. Dargó thanks the Gedeon Richter Talentum Foundation for the financial support.

[4] Priyakumar, U. D., Sastry G. N. "Cation- $\pi$ interaction of curved polycyclic systems: $\mathrm{M}^{+}(\mathrm{M}=\mathrm{Li}$ and $\mathrm{Na})$ ion complexation with buckybowls", Tetrahedron Letters, 44(32), pp. 6043-6046, 2003. https://doi.org/10.1016/S0040-4039(03)01512-0

[5] Lakowicz, J. R. "Principles of Fluorescence Spectroscopy", 3rd ed., Springer Science and Business Media, New York, NY., USA, 2006.

[6] Móczár, I., Huszthy, P. "Optically active crown ether-based fluorescent sensor molecules: A mini-review", Chirality, 31(2), pp. 97-109, 2019.

https://doi.org/10.1002/chir.23031 
[7] Móczár, I., Huszthy, P., Maidics, Z., Kádár, M., Tóth, K. "Synthesis and optical characterization of novel enantiopure BODIPY linked azacrown ethers as potential fluorescent chemosensors", Tetrahedron, 65(39), pp. 8250-8258, 2009.

https://doi.org/10.1016/j.tet.2009.07.061

[8] Móczár, I., Huszthy, P., Mezei, A., Kádár, M., Nyitrai, J., Tóth, K. "Synthesis and optical characterization of novel azacrown ethers containing an acridinone or a $\mathrm{N}$-methylacridinone unit as potential fluorescent chemosensors", Tetrahedron, 66(1), pp. 350-358, 2010. https://doi.org/10.1016/j.tet.2009.10.076

[9] Kertész, J., Móczár, I., Kormos, A., Baranyai, P., Kubinyi, M., Tóth, K., Huszthy, P. "Synthesis and enantiomeric recognition studies of dialkyl-substituted 18-crown-6 ethers containing an acridine fluorophore unit", Tetrahedron: Asymmetry, 22(6), pp. 684-689, 2011. https://doi.org/10.1016/j.tetasy.2011.03.011

[10] Szemenyei, B., Móczár, I., Pál, D., Kocsis, I., Baranyai, P., Huszthy, P. "Synthesis and Enantiomeric Recognition Studies of Optically Active Pyridine-Crown Ethers Containing an Anthracene Fluorophore Unit", Chirality, 28(7), pp. 562-568, 2016. https://doi.org/10.1002/chir.22614

[11] Németh, T., Tóth, T., Balogh, G. T., Huszthy, P. "Synthesis and Fluorescence Spectroscopic Studies of Novel 9-phenylacridino-18-crown-6 Ether Type Sensor Molecules", Periodica Polytechnica Chemical Engineering, 61(4), pp. 249-257, 2017 https://doi.org/10.3311/PPch.11277

[12] Pál, D., Móczár, I., Szemenyei, B., Marczona, D., Kocsis, I., Prikler, G., Vezse, P., Baranyai, P., Huszthy, P. "Pyridino-18crown-6 ether type chemosensors containing a benzothiazole fluorophore unit: synthesis and enantiomeric recognition studies", Tetrahedron, 75(20), pp. 2900-2909, 2019. https://doi.org/10.1016/j.tet.2019.04.024

[13] Szabó-Szentjóbi, H., Szabó, T., Tóth, T., Huszthy, P. "Crown ethers containing phosphorus in the macroring", In: Keglevich, Gy. (ed.) Organophosphorus Chemistry, Novel Developments, Walter de Gruyter, Berlin, Germany, 2018, pp. 284-308. https://doi.org/10.1515/9783110535839-015

[14] Huszthy, P., Samu, E., Vermes, B., Mezey-Vandor, G., Nogradi, M., Bradshaw, J. S., Izatt, R. M. "Synthesis of novel acridino- andphenazino-18-crown-6 ligands and their optically pure dimethyl-substituted analogs for molecular recognition studies", Tetrahedron, 55(5), pp. 1491-1504, 1999. https://doi.org/10.1016/S0040-4020(98)01128-4

[15] Jones, B. A., Bradshaw, J. S., Izatt, R. M. "The synthesis of chiral dimethyl substituted macrocyclic polyether-diester ligands", Journal of Heterocyclic Chemistry, 19(3), pp. 551-556, 1982. https://doi.org/10.1002/jhet.5570190320

[16] Huszthy, P., Farkas, V., Tóth, T., Székely, Gy., Hollósi, M. "Synthesis and preliminary studies on novel enantiopure crown ethers containing an alkyl diarylphosphinate or a proton-ionizable diarylphosphinic acid unit", Tetrahedron, 64(43), pp. 10107-10115, 2008. https://doi.org/10.1016/j.tet.2008.07.111

[17] Savle, P. S., Lamoreaux, M. J., Berry, J. F., Gandour, R. D. "A convenient resolution of long-chain alkyl epoxides with Jacobsen's salen(Co) III(OAc) catalysts", Tetrahedron: Asymmetry, 9(11), pp. 1843-1846, 1998 https://doi.org/10.1016/S0957-4166(98)00175-X
[18] Schaus, S. E., Brandes, B. D., Larrow, J. F., Tokunaga, M., Hansen, K. B., Gould, A. E., Furrow, M. E., Jacobsen, E. N. "Highly selective hydrolytic kinetic resolution of terminal epoxides catalyzed by chiral (salen)CoIII complexes. Practical synthesis of enantioenriched terminal epoxides and 1,2-diols", Journal of the American Chemical Society, 124(7), pp. 1307-1315, 2002. https://doi.org/10.1021/ja0167371

[19] Lamb, J. D., Izatt, R. M., Garrick, D. G., Bradshaw, J. S., Christensen, J. J. "The influence of macrocyclic ligand structure on carrier-facilitated cation transport rates and selectivities through liquid membranes", Journal of Membrane Science, 9(1-2), pp. $83-107,1981$ https://doi.org/10.1016/S0376-7388(00)85119-4

[20] Szabó, T., Petri, L., Gergely, Sz., Huszthy, P. "Synthesis of achiral and new chiral crown ethers containing a triphenylphosphane unit", Arkivoc, 2015(5), pp. 20-33, 2015. https://doi.org/10.3998/ark.5550190.p009.075

[21] Jovic, F., Louise, L., Mioskowski, C., Renard, P. Y. "Immunologically driven antibodies chemical engineering: design and synthesis of a hapten aimed at nerve agent hydrolysis", Tetrahedron Letters, 46(40), pp. 6809-6814, 2005. https://doi.org/10.1016/j.tetlet.2005.08.032

[22] Oshikawa, T., Seo, K., Yamashita, M., Hanaya, H., Hamauzu, Y., Yamamoto, H. "Synthesis and structure analyses of 1,2,4-tri-O-acetyl-3,5-di-deoxy-5-C-(isopropyl- and phenyl-phosphinyl)-D-erythro-pentopyranoses", Heterocyclic Communications, 9(6), pp. 559566,. 2003.

https://doi.org/10.1515/HC.2003.9.6.559

[23] Seo, K. ",A new route for formation of the carbon-phosphorus bond, and synthesis of 1,2,4-tri-O-acetyl-5-deoxy-3-O-methyl5-C-[(R)- and (S)-Phenylphosphinyl]- $\alpha$ - and $\beta$-D-xylopyranose", Carbohydrate Research, 119, pp. 101-107, 1983. https://doi.org/10.1016/0008-6215(83)84049-X

[24] Collins, D. J., Drygala, P. F., Swan, J. M. "Organophosphorus Compounds. XVIII. Synthesis of 2-phenyl-2,3-dihydro-1H-1,2-benzazaphosphole 2-sulfide by pyrolysis of (2-aminobenzyl)-phenyldithiophosphinic acid", Australian Journal of Chemistry, 36, pp. 2095-2110, 1983. https://doi.org/10.1071/CH9832095

[25] van de Weert, M., Stella, L. "Fluorescence quenching and ligand binding: A critical discussion of a popular methodology", Journal of Molecular Structure, 998(1-3), pp. 144-150, 2011. https://doi.org/10.1016/j.molstruc.2011.05.023

[26] Szabó-Szentjóbi, H., Bagi, P., Müller, J., Balogh, G. T., Tóth, T., Huszthy, P. "Synthesis and enantioselective transport studies of both enantiomers of new chiral proton-ionizable crown ethers containing a diarylphosphinic acid unit", Tetrahedron, 75(9), pp. 1275-1281, 2019. https://doi.org/10.1016/j.tet.2019.01.039

[27] Riddick, J. A., Bunger, W. B., Sakano, T. K. "Organic Solvents: Physical Properties and Methods of Purification", In: Weissberger, A. (ed.) Techniques of Chemistry, 4th ed., WileyInterscience, New York, NY, 1986.

[28] Köntös, Z., Huszthy, P., Bradshaw, J. S., Izatt, R. M. "Enantioseparation of racemic organic ammonium perchlorates by a silica gel bound optically active di-tert-butylpyridino18-crown-6 ligand", Tetrahedron: Asymmetry, 10(11), pp. 2087-2099, 1999. https://doi.org/10.1016/S0957-4166(99)00163-9 